\title{
Influence of environmental conditions and oxidation on the coefficient of friction using microalloyed rail steels
}

\author{
J. L. Viesca ${ }^{\mathrm{a}, \mathrm{b}, *}$, S. González-Cachón ${ }^{\mathrm{a}}, \mathrm{A}$. García ${ }^{\mathrm{a}}, \mathrm{R}$. González ${ }^{\mathrm{c}, \mathrm{b}}$ \\ A. Bernardo-Sánchez ${ }^{\mathrm{d}}$, A. Hernández Battez ${ }^{\mathrm{a}, \mathrm{b}}$ \\ ${ }^{\text {a }}$ Department of Construction and Manufacturing Engineering, University of Oviedo, Asturias, Spain \\ ${ }^{\mathrm{b}}$ Faculty of Science and Technology, Bournemouth University, UK \\ ${ }^{c}$ Department of Marine Science and Technology, University of Oviedo, Asturias, Spain \\ ${ }^{\mathrm{d}}$ Department of Mining, Topographic and Structures Technology, University of Leon, Leon, Spain \\ (*) Email: viescajose@uniovi.es / Orcid ID: 0000-0002-9838-8634
}

\begin{abstract}
In railway systems, certain atmospheric conditions mainly related to temperature and relative humidity lead to the creation of iron oxides which can affect the coefficient of friction between wheel and rail. This can result in increased wear of the rail, reducing its service life and thus increasing replacement costs. Pin-ondisc tests were conducted in a climate chamber to study the influence of environmental conditions and iron oxides on the coefficient of friction (COF). The iron oxides generated on the surface of specimens extracted from microalloyed rail steel during wear tests were analysed using X-ray diffraction (XRD).

The results show that hematite $\left(\alpha-\mathrm{Fe}_{2} \mathrm{O}_{3}\right)$ is the predominant iron oxide among all the oxides generated on the worn surfaces. It was further noted that the oxide layer resulting from the rise in both temperature and relative humidity does not significantly affect the average coefficient of friction for each steel samples tested. High relative humidity combined with high temperature leads to the formation of hematite iron oxide $\left(\alpha-\mathrm{Fe}_{2} \mathrm{O}_{3}\right)$, which tends to increase COF. However, a boundary lubrication effect is observed at higher relative humidity due to a condensed water film, which reduce the COF and counteracts the COF increase expected due to the presence of hematite.
\end{abstract}

Keywords: microalloyed rail steel; friction; pin-on-disc; iron oxide; X-ray diffraction.

\section{Introduction}

Good adhesion between rail and wheel is an essential requirement for the safe, efficient and reliable operation of a rail network. This aspect requires an optimum coefficient of friction (COF) given that this factor greatly influences the traction and braking of the railway vehicle [1]. It is therefore essential to identify the most suitable value of COF for the specific conditions of wheel-rail contact that would prevent wheel slippage, thus reducing rail wear, energy consumption in traction and maintenance costs, all of which lead to a significant increase in the lifespan of the rail [2].

The COF should be adequate (neither too high nor too low), given that inadequate friction can cause serious damage to railway infrastructure. Excessively high COF values will lead to higher energy consumption and severe rail wear due to plastic deformation and 
increased rolling contact fatigue on the surface of the rails. If the COF is too low, this can limit the traction and braking of railway vehicles, thereby leading to an increase in braking distance or to engine burns. Several studies about wheel-rail friction and adhesion have been conducted by using different instruments ranging from laboratory devices to full-scale rigs. These experiments were conducted under different test conditions (dry rail, wet rail, greasy rail, and so on) producing coefficient of friction values from 0.1 to 0.7 [3-4]. Typical approaches to preventing and mitigating the effects of poor friction between wheel and rail are the use of friction modifiers (used to control rail-head contamination) and grinding [5].

The main factors that affect the COF in wheel-rail contact are environmental conditions and the iron oxides generated on the surface of the rail. Some authors have investigated the influence of environmental conditions (temperature and humidity) and iron oxides on the COF of the wheel-rail contact. Lewis et al. [6] analysed the effects of atmospheric variations and oxide conditions on the performance of friction modifiers. The study used a pin-on-disc test rig enclosed in a climate chamber and the results showed that relative humidity has strong influence on how friction modifier affects friction levels and the amount of time it remains on the disc. Faccoli et al. [7] correlated the COF obtained employing a pin-on-disc configuration with that obtained using a twin-disc configuration. The findings demonstrated that the pin-on-disc configuration is a good choice as a screening method for testing wheel-rail contact materials, as it is a simpler and less expensive technique than others commonly employed for this purpose.

Hayashi et al. [8] showed that rail temperature and relative humidity strongly influence adhesion between rails and wheels. Meanwhile, Olofsson and Sundvall [9] showed that the value of the COF decreases with increasing relative humidity, an effect which is even more pronounced when a rail lubricant is used. 
Ishida et al. [10] reported that iron oxides generated on the surface of the rail influence the coefficient of friction. White et al. [11] reported the formation of iron oxide in wheelrail contact at atmospheric conditions and determined their influence on friction. They referred to five types of iron oxides: hematite or $\mathrm{Fe}_{2} \mathrm{O}_{3}$ (increases friction), magnetite or $\mathrm{Fe}_{3} \mathrm{O}_{4}$ (decreases friction), goethite or $\alpha-\mathrm{FeOOH}$ (decrease friction), akaganeite or $\beta$ $\mathrm{FeOOH}$ (decreases friction) and lepidocrocite or $\gamma$-FeOOH (unknown impact on friction). Lee et al. [12] reported that hematite $\left(\alpha-\mathrm{Fe}_{2} \mathrm{O}_{3}\right)$ and maghemite- $\mathrm{C}\left(\gamma-\mathrm{Fe}_{2} \mathrm{O}_{3}\right)$ are the main chemical species of iron oxides found on the rails in underground railway tunnels and Querol [13] revealed that the bulk of Fe-particles are present in the form of hematite. On the other hand, Zhu et al. [14] showed that hematite $\left(\alpha-\mathrm{Fe}_{2} \mathrm{O}_{3}\right)$ is the predominant iron oxide on the surface of the rail and its presence tends to increase the COF. They also found that the water molecule film resulting from the increase of relative humidity counteracts the effect of the hematite reducing the friction coefficient. In addition, the COF stabilizes when neither of the two effects is dominant. That study also showed that iron oxides could be created by using a pre-treatment of the specimens taken from rails and wheels in a climate chamber. This procedure was suggested by Suzumura et al. [15], who demonstrated that the in-situ X-ray diffraction (XRD) analysis method is the most effective to identify the type of oxide produced on the rail surface.

Lyu et al. [16] investigated the effects that different environmental conditions (humidity and temperature) and the oxide layers thus generated have on the wear performance of a pin extracted from UIC 900A rail. The results of the study showed that a low value of relative humidity $(40 \% \mathrm{RH})$ causes adhesive wear and under high relative humidity $(85 \%$ $\mathrm{RH})$ the main wear mechanism is oxidative wear. The oxide layers formed on the surface consisted of $\mathrm{Fe}_{3} \mathrm{O}_{4}$ and $\mathrm{Fe}_{2} \mathrm{O}_{3}$. 
The development of new rail steels with better mechanical properties, such as microalloyed steels, to withstand high temperatures and humidity is an important current goal for railway companies. Nonetheless, little research has been published to date on the friction behavior of microalloyed rail steels. Panda et al. [17-18] analysed the nature of the oxide generated on microalloyed steel rails compared to traditional C-Mn steel rails, finding that microalloyed rail steels have a greater corrosion resistance than commonly used C-Mn rail steels.

The atmospheric conditions (temperature and relative humidity) and iron oxides formation could also influence the friction in wheel-rail contact using microalloyed steel due to its less tendency to form oxides and lower corrosion rate than the common C-Mn rail steel. With the exception of a previous paper by the authors [19], to the best of our knowledge, no studies have examined the effect of environmental conditions (temperature and humidity) on the coefficient of friction using microalloyed steels.

The aim of this paper is to study the COF behaviour when using a microalloyed steel under different environmental conditions (temperature and humidity) in the presence of iron oxides. Statistical analysis of COF values as a function of test time and XRD analysis of wear debris were used for this purpose.

\section{Experimental procedure}

\subsection{Materials}

The pins to be used in the tribological tests were manufactured from microalloyed rail steel (profile 115RE) and R260 grade C-Mn rail steel (profile 54E1) in accordance with previous work [19]. Discs were manufactured from R260 grade C-Mn rail steel due to its similar properties to that of the wheels' material [20]. The mechanical properties of the tested steels are shown in Table $\mathbf{1 .}$ 
Table 1. Mechanical properties of tested steels [19].

\begin{tabular}{lccccc}
\hline Sample & $\begin{array}{c}\text { Rail } \\
\text { profile }\end{array}$ & Hardness HB & $\boldsymbol{\sigma}_{\mathbf{y}}{ }^{a} \mathbf{M P a}$ & $\mathbf{R}^{\mathbf{b}} \mathbf{M P a}$ & $\mathbf{A}_{\mathbf{5}}{ }^{\mathbf{c}} \mathbf{0}$ \\
\hline R260 & $54 \mathrm{E} 1$ & 249 & 528 & 951 & 13 \\
Microalloyed & $115 \mathrm{RE}$ & 292 & 677 & 1150 & 10 \\
\hline
\end{tabular}

${ }^{\mathrm{a}} \boldsymbol{\sigma}_{\mathrm{y}}=$ Yield Strength, ${ }^{\mathrm{b}} \mathrm{R}=$ Ultimate strength, ${ }^{\mathrm{c}} \mathrm{A}_{5}=$ Elongation

\subsection{Tribological tests}

A Bruker UMT-3 tribometer with a pin-on-disc configuration and a climate chamber with temperature and humidity control were used for the tribological tests. The tested tribological pairs were formed by pins of R260 and microalloyed steels (representing the rail) and discs of R260 steel (representing the wheel). The COF was measured in real time during the tests. The measurement readings were automatically taken every 3.05 seconds by the tribometer (according to the device's default data acquisition frequency for 1 hour tests), thus providing 1181 measurements in 1 hour. Statistical methods such as frequency tables were used to further study the coefficient of friction behaviour. A bar chart (histogram) was used to interpret the results of the frequency tables [21].

Tests were divided into four series: Series 1 was performed at a temperature of $20^{\circ} \mathrm{C}$ and three relative humidity values $(15,42.5$ and $70 \% \mathrm{RH})$, Series 2 and 4 were made at a temperature of $40{ }^{\circ} \mathrm{C}$ and two relative humidity values (15 and $\left.70 \% \mathrm{RH}\right)$, and Series 3 used a temperature of $20^{\circ} \mathrm{C}$ and two relative humidity values (15 and $\left.70 \% \mathrm{RH}\right)$. Table 2 shows the experimental details of each series. Each test was repeated three times and the results were averaged. 
Table 2. Test parameters of the series.

\begin{tabular}{ccccc}
\hline Series & $\begin{array}{c}\text { Test } \\
\text { number }\end{array}$ & Sample & $\begin{array}{c}\text { Temperature } \\
\left({ }^{\circ} \mathbf{C}\right)\end{array}$ & $\begin{array}{c}\text { Relative Humidity } \\
(\mathbf{\%})\end{array}$ \\
\hline S1 & 1.1 & Microalloyed & 20 & 70 \\
S1 & 1.3 & Microalloyed & 20 & 42.5 \\
S1 & 1.2 & Microalloyed & 20 & 15 \\
S2 & 2.1 & Microalloyed & 40 & 70 \\
S2 & 2.2 & Microalloyed & 40 & 15 \\
S3 & 3.1 & R260 & 20 & 70 \\
S3 & 3.2 & R260 & 20 & 15 \\
S4 & 4.1 & R260 & 40 & 70 \\
S4 & 4.2 & R260 & 40 & 15 \\
\hline
\end{tabular}

The pin-on-disc tests were carried out under a normal load of $20 \mathrm{~N}$ at $200 \mathrm{rpm}(0.35 \mathrm{~m} / \mathrm{s}$ sliding speed), with a 60 min duration (sliding distance $=1.28 \mathrm{~km}$ ). The test duration was selected in order to obtain representative COF values (minimizing the influence of the test's running-in period). The higher $\mathrm{RH}$ value studied (70\%) corresponds to the typical conditions in humid environments, where a high wear rate has been found. On the other hand, the lower $\mathrm{RH}$ value studied (15\%) corresponds to typical conditions in dry environments. The combination of a temperature of $40{ }^{\circ} \mathrm{C}$ with $15 \% \mathrm{RH}$ constitutes the characteristic conditions of an arid environment.

\section{$2.3 X$-ray diffraction}

The primary aim of this analysis was to assess and identify the different oxides generated on the worn surfaces of the samples after the tribological tests. The X-ray diffraction (XRD) method used was powder X-ray diffraction. The X-ray powder diffractogram of wear debris provides the signal intensity data per diffraction angle, producing a series of peaks which allow the analysis of the crystalline phases.

The X-ray powder diffraction was performed on a PANalytical X'Pert Powder diffractometer equipped with a $\mathrm{Cu}$ tube. The Bragg-Brentano parafocusing configuration was used in a synchronous rotation of sample-detector omega-2 theta and scanning mode with constant velocity of $0.01 \%$ s. Measurements were carried out on the surface of the pin 
and also on the debris obtained with a waterproof sandpaper P2000. The Powder Diffraction File, a database of powder diffraction patterns, was used for qualitative identification of the iron oxides present in the samples.

\section{Results and discussion}

\subsection{Tribological tests under different atmospheric conditions (temperature and humidity)}

Figure 1 compares the evolution of the coefficient of friction versus time using a pin from microalloyed steel under different relative humidity values and temperature of $20{ }^{\circ} \mathrm{C}$. The friction behaviour seems to be similar irrespective the relative humidity.

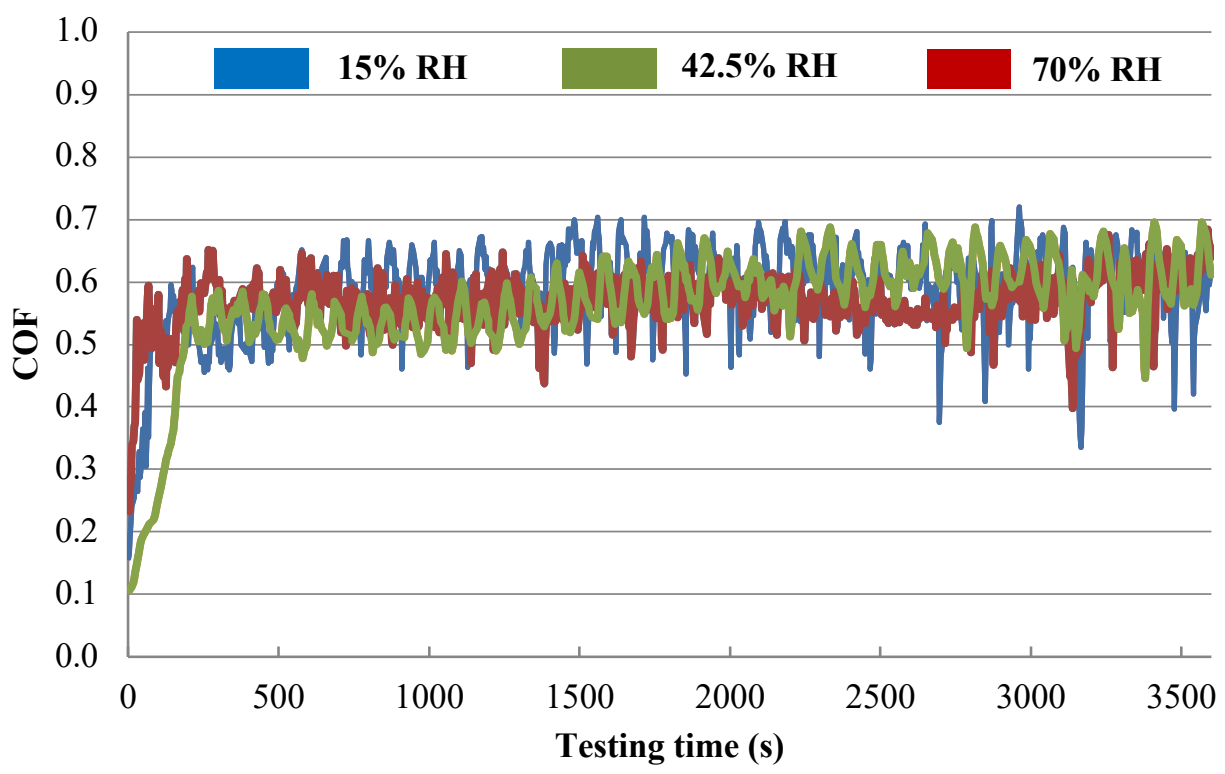

Figure 1. Evolution of the COF during the tribological tests using microalloyed steel at $20^{\circ} \mathrm{C}$ and $15,42.5$ and $70 \% \mathrm{RH}$.

For the steel-steel contact under clean conditions, the average coefficient of friction is approximately 0.6 , which widely exceeds all adhesion requirements [4]. It is possible that corrective processes to reduce the $\mathrm{COF}$, such as the use of friction modifiers could be required.

As can be seen in Table 3, the highest percentage of measured points of the COF for the lowest relative humidity $(15 \% \mathrm{RH})$ ranges between 0.6 and 0.7 . On the other hand, the highest percentage of measured points of the COF for the highest relative humidity $(70 \%$ 
$\mathrm{RH}$ ) ranges between 0.5 and 0.6 . This means that during the tribological tests under the lowest relative humidity, the coefficient of friction remains at high values $(0.6-0.7)$ for a longer time than during the tribological tests under the highest relative humidity.

Table 3. Frequency table of the instantaneous friction values from tribological tests using microalloyed steel at $20^{\circ} \mathrm{C}$ and $15,42.5$ and $70 \% \mathrm{RH}$.

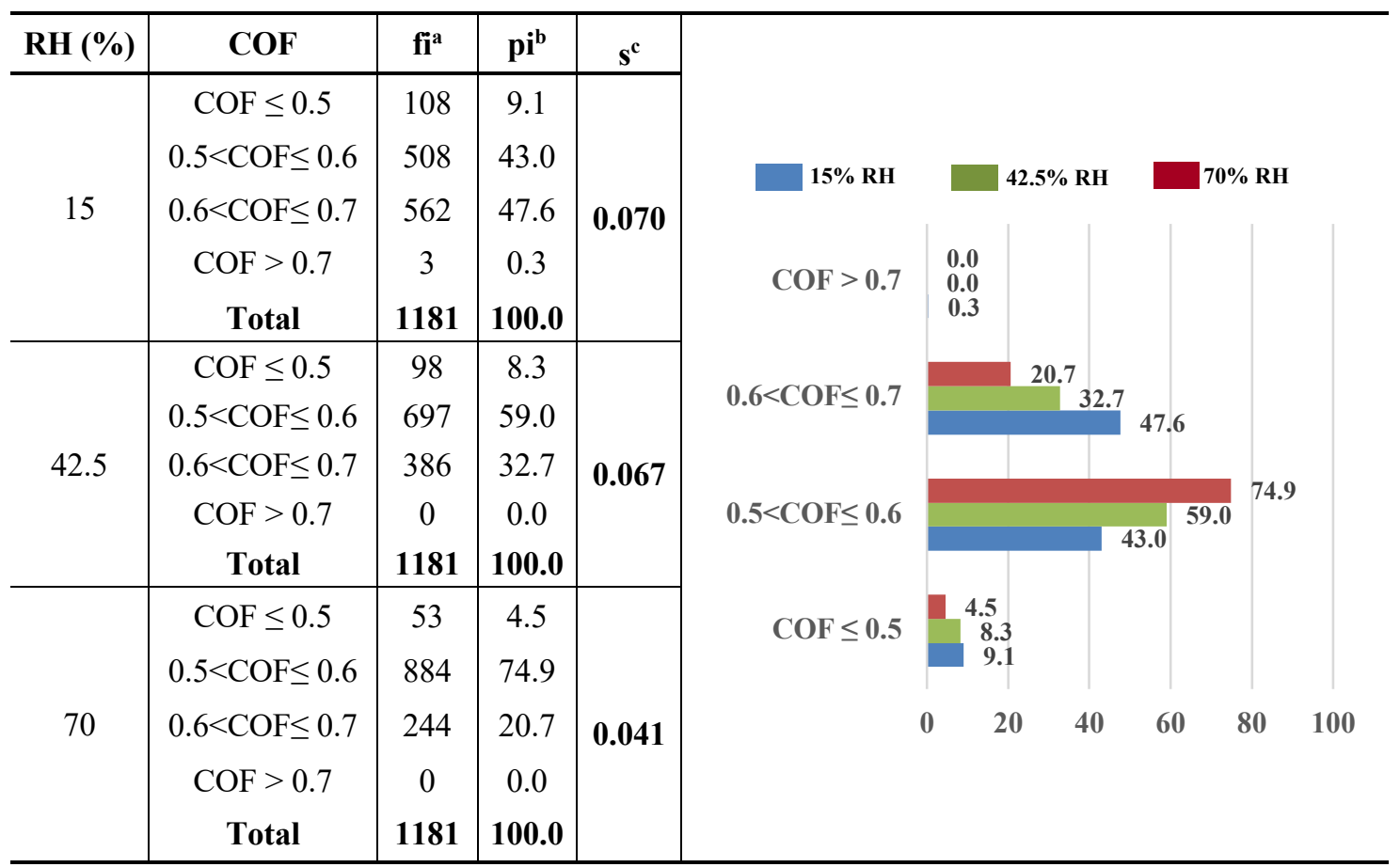

${ }^{\mathrm{a}} \mathrm{fi}=$ Absolute frequency, ${ }^{\mathrm{b}} \mathrm{pi}=$ Relative frequency, ${ }^{\mathrm{c}} \mathrm{s}=$ Standard deviation

Comparing the results at $20^{\circ} \mathrm{C}$ (Table 3 ) and $40{ }^{\circ} \mathrm{C}$ (Table 4), the coefficient of friction decreases with increasing relative humidity. The COF for tribological tests under lower relative humidity remains at higher values $(0.6-0.7)$ for a longer time than during the tribological tests under higher relative humidity $(0.5-0.6)$. From the standard deviation data (Tables 3 and 4) it can be concluded that the variation in the COF is higher at lower relative humidity. This phenomenon is related to the condensation of water and the boundary water lubrication effect. 
Table 4. Frequency table of the instantaneous friction values from tribological tests using microalloyed steel at $40{ }^{\circ} \mathrm{C}$ and $15,42.5$ and $70 \% \mathrm{RH}$.

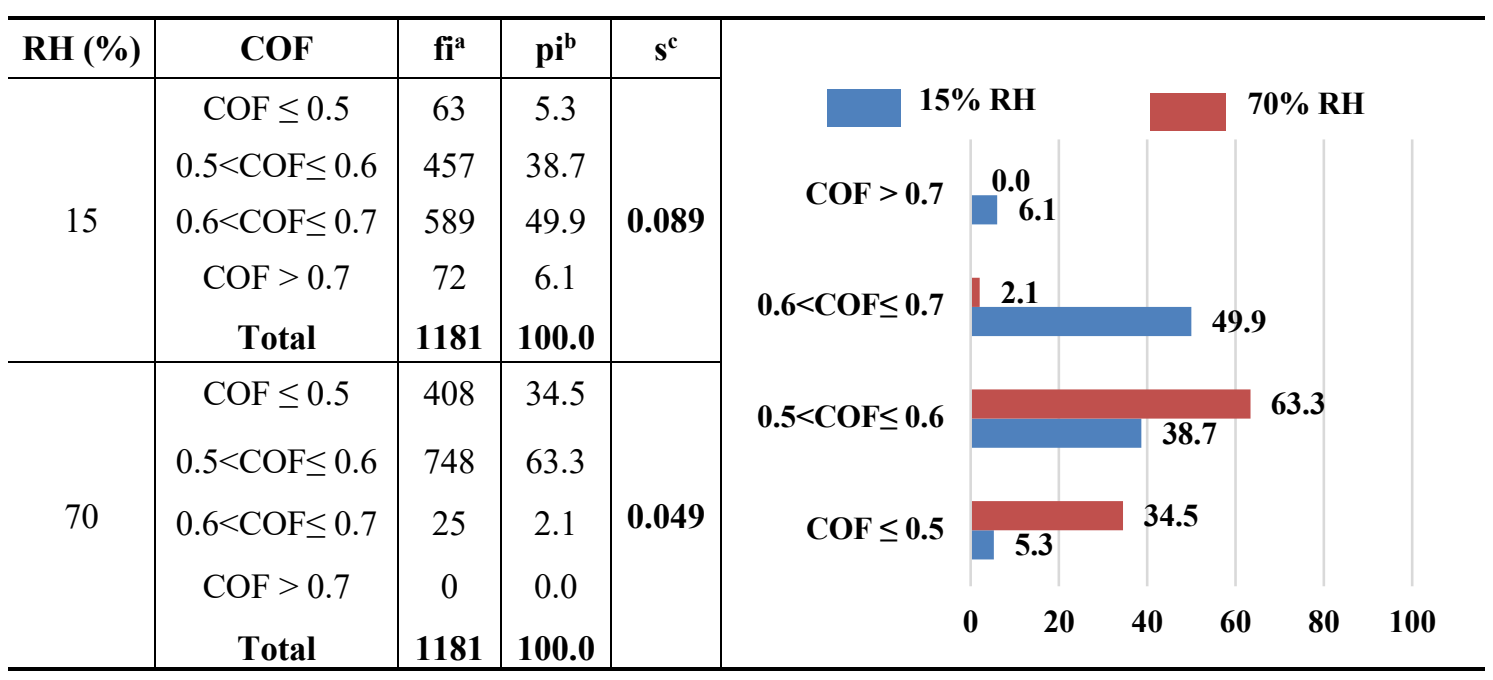

${ }^{\mathrm{a}} \mathrm{fi}=$ Absolute frequency, ${ }^{\mathrm{b}} \mathrm{pi}=$ Relative frequency, ${ }^{\mathrm{c}} \mathrm{s}=$ Standard deviation

According to the results reported in Tables 3-6, differences in friction coefficient were found in tests made with both steels (microalloyed and R260). Higher friction values were measured for the R260 steel. This can be seen from the comparative tables of frequency between the microalloyed rail steel and the R260 rail steel (Tables 3 and 5 at $20{ }^{\circ} \mathrm{C}$; Tables 4 and 6 at $40{ }^{\circ} \mathrm{C}$ ), where the highest percentage of measured points of the COF for the microalloyed rail steel ranges between 0.5 and 0.6 , while the highest percentage of measured points of the COF for the R260 rail steel is higher than 0.6. 
Table 5. Frequency table of the instantaneous friction values from tribological tests using the R260 specimen at $20^{\circ} \mathrm{C}$ and 15 and $70 \% \mathrm{RH}$.

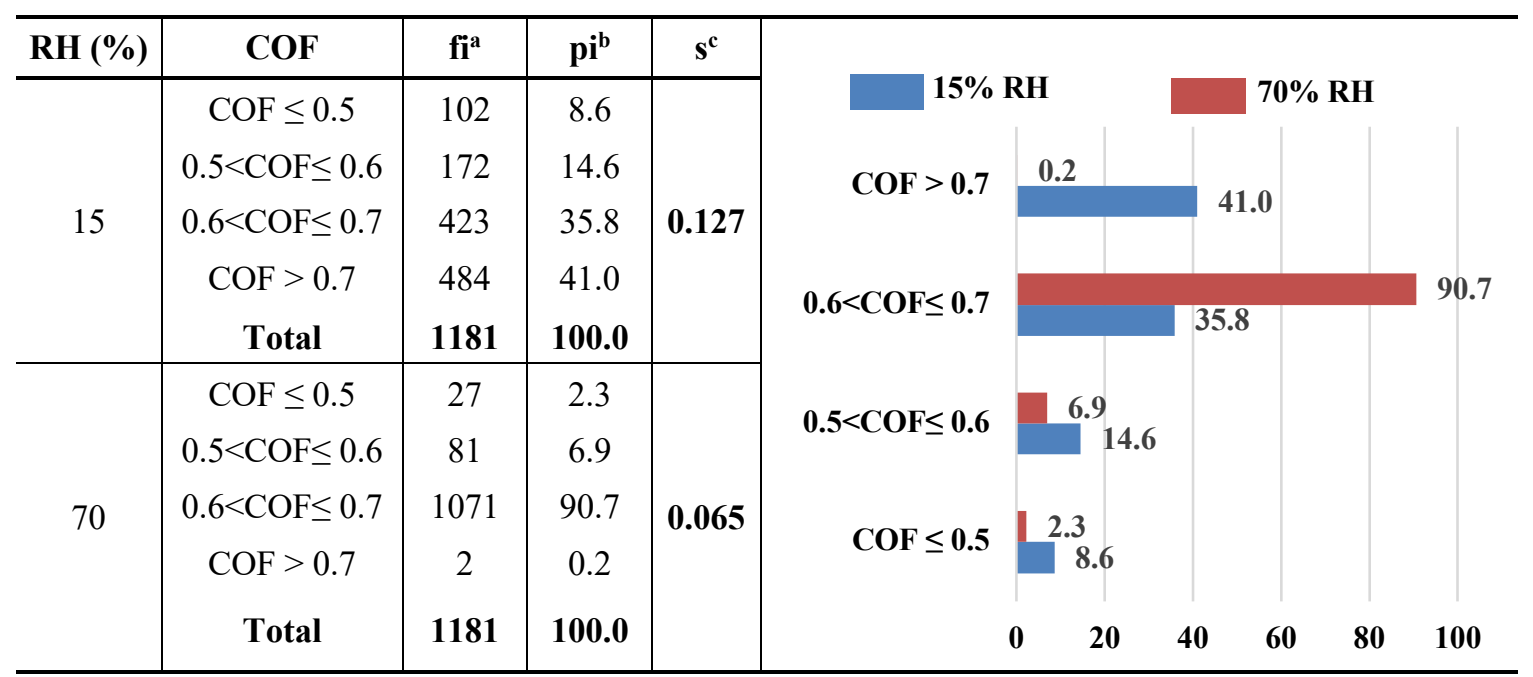

${ }^{\mathrm{a}} \mathrm{fi}=$ Absolute frequency, ${ }^{\mathrm{b}} \mathrm{pi}=$ Relative frequency, ${ }^{\mathrm{c}} \mathrm{s}=$ Standard deviation

Table 6. Frequency table of the instantaneous friction values from tribological tests using the R260 specimen at $40{ }^{\circ} \mathrm{C}$ and 15 and $70 \% \mathrm{RH}$.

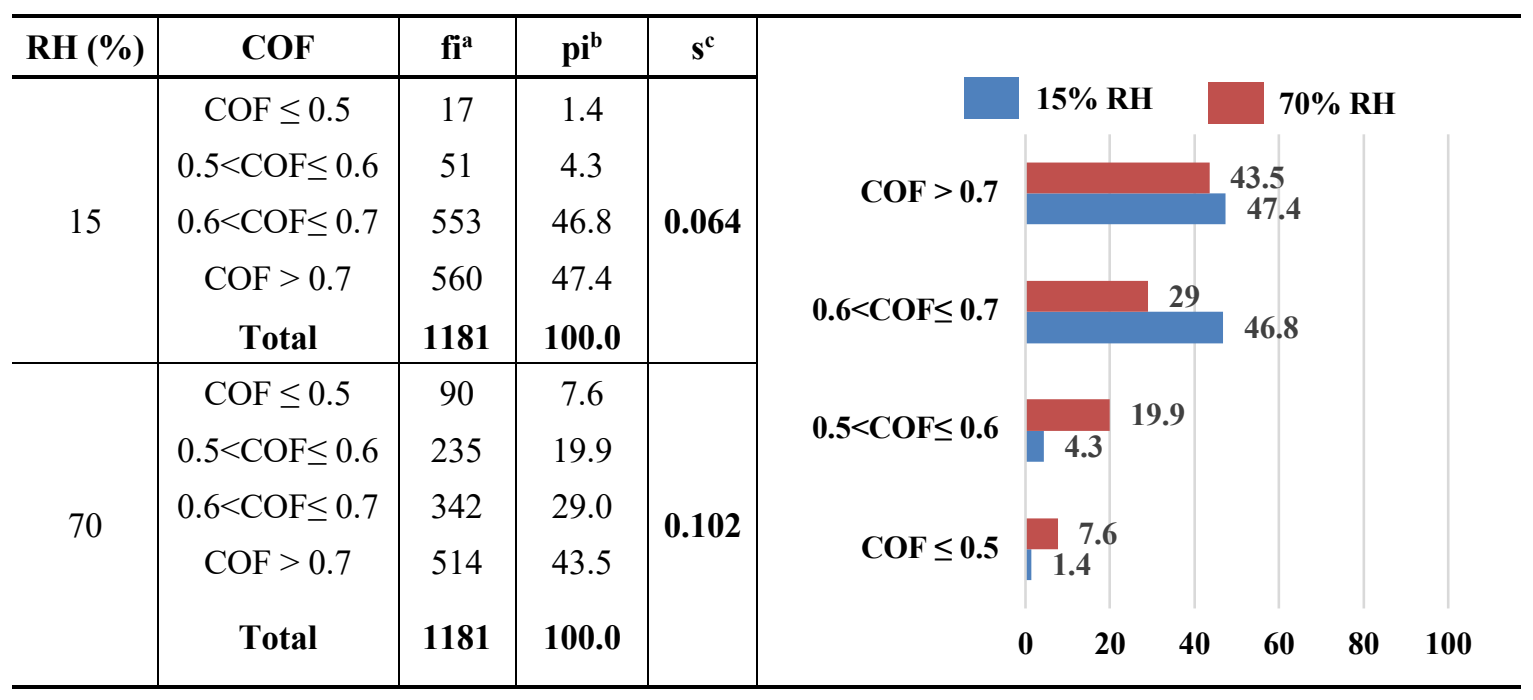

${ }^{\mathrm{a}} \mathrm{fi}=$ Absolute frequency, ${ }^{\mathrm{b}} \mathrm{pi}=$ Relative frequency, ${ }^{\mathrm{c}} \mathrm{s}=$ Standard deviation

Wear mechanisms observed in all tests for both microalloyed and R260 steels correspond mainly to adhesive and oxidative wear. Figure 2 shows the adhesive wear observed on the surfaces of microalloyed steel for $20 \%$ and $70 \%$ RH. No significant differences were observed between both steel samples. 

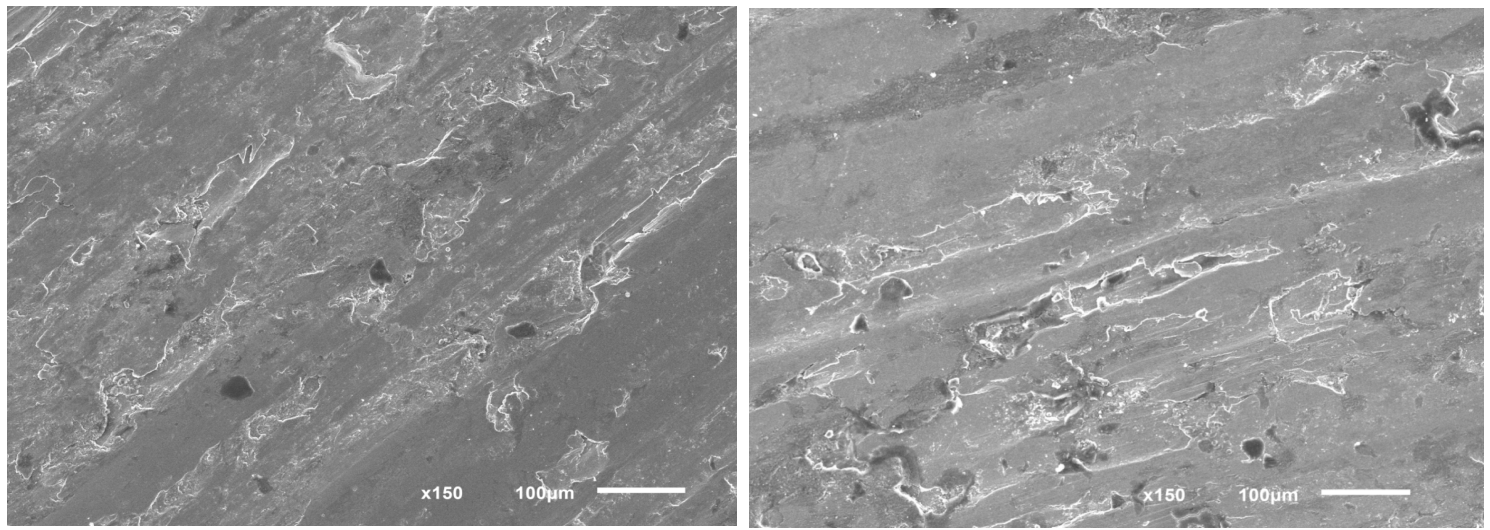

Figure 2. Micrographs of wear scar for microalloyed steel specimens after tests performed at $20{ }^{\circ} \mathrm{C}$ and $15 \% \mathrm{RH}$ (left) and $70 \% \mathrm{RH}$ (right).

Relative humidity affects coefficient of friction due to the boundary lubrication effect generated by the water condensation film on the wear track. Water condensation generated in the high humidity test $(70 \% \mathrm{RH})$ explains the lower COF values. This phenomenon was described by Blau [22] in metal tribopairs under dry sliding conditions. A condensed water film usually reduces the coefficient of friction, but when combined with high temperature could generate more corrosion. The COF can increase or decrease depending on the type of oxides generated [11].

For the microalloyed steel samples tested at $15 \% \mathrm{RH}$, the evolution of the COF for both temperatures studied $\left(20\right.$ and $40{ }^{\circ} \mathrm{C}$ ) was similar under the test conditions employed, with no significant differences. However, the microalloyed steel samples tested at $70 \% \mathrm{RH}$ presented a decrease in COF values with increasing temperature. 


\section{$3.2 X$-ray diffraction}

The purpose of this analysis was to identify the different oxides generated on the worn surfaces of microalloyed steel pins (more corrosion-resistant than C-Mn steel pins) after the wear tests made under different temperature and humidity conditions. Four wear test specimens were analysed using the powder XRD technique. The tested specimens correspond to the test numbers: $2.1\left(70 \% \mathrm{RH}\right.$ and $\left.40{ }^{\circ} \mathrm{C}\right), 1.1\left(70 \% \mathrm{RH}\right.$ and $\left.20{ }^{\circ} \mathrm{C}\right), 2.2$ $\left(15 \% \mathrm{RH}\right.$ and $\left.40{ }^{\circ} \mathrm{C}\right)$ and $1.2\left(15 \% \mathrm{RH}\right.$ and $\left.20^{\circ} \mathrm{C}\right)$.

Figure 3 shows the X-ray powder diffractogram for test number $2.1\left(70 \% \mathrm{RH}\right.$ and $\left.40{ }^{\circ} \mathrm{C}\right)$, which corresponds to the most severe test, where environmental conditions are most favourable to the formation of oxides. Although no definitive result was obtained due to the low number and intensity of the available reflection, the presence of hematite ( $\alpha$ $\mathrm{Fe}_{2} \mathrm{O}_{3}$ ) is most likely, as three characteristic peaks of hematite can be identified in Figure 3. The findings of this study are in good agreement with the results reported in Querol et al. [13], in which hematite $\left(\alpha-\mathrm{Fe}_{2} \mathrm{O}_{3}\right)$ was found to be the predominant iron oxide under moist conditions among the oxides generated on the rail-head surface. Fe metallic characteristic peaks were also detected with greater intensity than the hematite peaks: mainly $\mathrm{Fe}(110)$ at $\approx 44.5^{\circ}, \mathrm{Fe}(200)$ at $\approx 64.8^{\circ}$ and $\mathrm{Fe}(211)$ at $\approx 82.2^{\circ}$. 


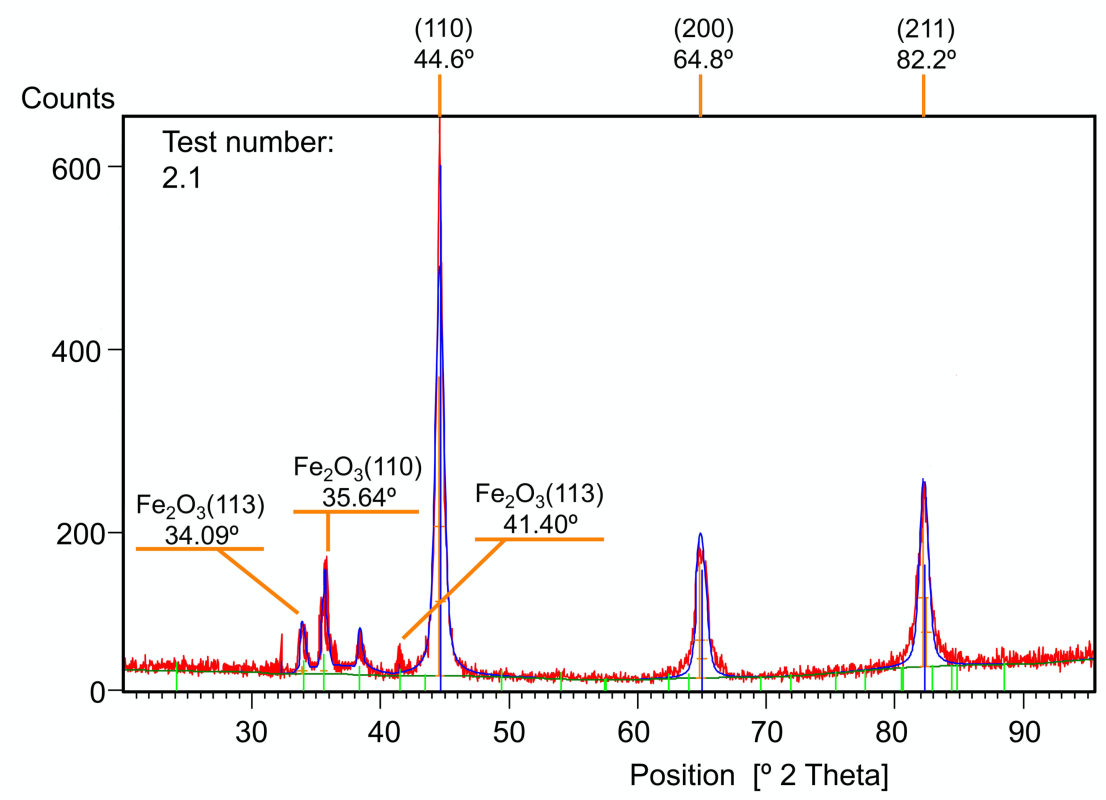

Figure 3. X-ray powder diffractogram for test number $2.1\left(70 \% \mathrm{RH}\right.$ and $\left.40^{\circ} \mathrm{C}\right)$.

The low percentage of oxides generated in the most severe test (test number 2.1) means that the study of the oxides produced under the other environmental conditions is practically unfeasible. The XRD diffractograms of tests number 1.1, 1.2 and 2.2 show the main characteristic peaks in the position of $\mathrm{Fe}(110)$ at $\approx 44.5^{\circ}, \mathrm{Fe}(200)$ at $\approx 64.8^{\circ}$ and $\operatorname{Fe}(211)$ at $\approx 82.2^{\circ}$, while the characteristic peaks of hematite $\left(\approx 34.1^{\circ}, \approx 35.6^{\circ}\right.$ and $\approx 41.4^{\circ}$ positions) are too small to conclusively identify hematite formation in these three samples. One of the reasons for the low number and intensity of the available reflection is because the affected area of the pin sample is too small for XRD analysis after pin-ondisc testing. A further reason is that microalloyed rail steel is more corrosion resistant than R260 rail steel and hence presents less oxide formation on its surface. The small amount of oxides found on the surface make it difficult to establish a definite correlation between coefficient of friction and the iron oxides detected. 


\section{Discussion}

Taking into account earlier findings, high levels of humidity produce the effect of boundary lubrication: a condensed water film is formed, thereby reducing the coefficient of friction. This phenomenon could explain the finding that the COF is slightly higher for the lowest relative humidity studied $(15 \% \mathrm{RH})$, meanwhile the COF decreased at $70 \%$ RH (Tables 3-7).

Furthermore, in accordance with the X-ray diffraction study (Figure 3), hematite ( $\alpha$ $\left.\mathrm{Fe}_{2} \mathrm{O}_{3}\right)$ is the predominant iron oxide under moist conditions among the oxides generated on the surface of the microalloyed rail sample. On the other hand, Zhu et al. [14] showed that the condensed water film counteracts the hematite $\left(\alpha-\mathrm{Fe}_{2} \mathrm{O}_{3}\right)$ on the surface, which tends to decrease the coefficient of friction. However, White et al. [12] showed that the coefficient of friction increased depending on the type of iron oxide in the wheel-rail contact.

Even though the distribution of the instantaneous friction values versus testing time, the average friction coefficient for each steel did not change a lot regardless of temperature and relative humidity (Table 7). Nonetheless, the average COF for the microalloyed rail steel samples is slightly lower than that of the R260 rail steel samples for all tested conditions. This is because microalloyed rail steel is more corrosion resistant than R260 rail steel [17-18] and less prone to the formation of hematite on the surface of the rail head. It can thus be concluded that reduced oxidation of microalloyed rail steel leads to a decrease in the coefficient of friction. 
Table 7. Average measured coefficient of friction.

\begin{tabular}{ccccccc}
\hline Series & $\begin{array}{c}\text { Test } \\
\text { number }\end{array}$ & Material & Temperature $\left({ }^{\circ} \mathbf{C}\right)$ & $\begin{array}{c}\text { Relative } \\
\text { Humidity } \\
(\%)\end{array}$ & $\begin{array}{c}\text { Average } \\
\text { COF }\end{array}$ & $\begin{array}{c}\text { Standard } \\
\text { deviation }\end{array}$ \\
\hline S1 & 1.1 & Microalloyed & 20 & 70 & 0.570 & 0.015 \\
S1 & 1.3 & Microalloyed & 20 & 42.5 & 0.564 & 0.041 \\
S1 & 1.2 & Microalloyed & 20 & 15 & 0.587 & 0.095 \\
S2 & 2.1 & Microalloyed & 40 & 70 & 0.521 & 0.039 \\
S2 & 2.2 & Microalloyed & 40 & 15 & 0.599 & 0.062 \\
S3 & 3.1 & R260 & 20 & 70 & 0.645 & 0.019 \\
S3 & 3.2 & R260 & 20 & 15 & 0.652 & 0.054 \\
S4 & 4.1 & R260 & 40 & 70 & 0.665 & 0.016 \\
S4 & 4.2 & R260 & 40 & 15 & 0.691 & 0.045 \\
\hline
\end{tabular}

\section{Conclusions}

From the results obtained in this study, the following conclusions can be drawn:

- The evolution of the coefficient of friction versus time when using microalloyed steel had a similar behaviour under all the environmental conditions studied.

- Hematite $\left(\alpha-\mathrm{Fe}_{2} \mathrm{O}_{3}\right)$ is the predominant iron oxide among the oxides generated on the worn surfaces of the microalloyed rail steel samples.

- At higher relative humidity, a boundary lubrication effect is generated due to a condensed water film that reduces the coefficient of friction. On the other hand, the condensed water film counteracts the effect of hematite $\left(\alpha-\mathrm{Fe}_{2} \mathrm{O}_{3}\right)$ on the surface, which tends to increase the coefficient of friction.

- The oxide layer caused by the increase in both temperature and relative humidity does not significantly affect the average coefficient of friction for each steel samples tested. 


\section{Acknowledgments}

The authors wish to thank the Foundation for the Promotion of Applied Scientific Research and Technology in Asturias (FICYT) for providing support for this study within the framework of the "Lubrication and Surface Technology - LUSUTEC" (FC-GRUPINIDI/2018/000131) research project.

\section{References}

1. Foo D, Badrul O. A review on recent wheel/rail interface friction management. Journal of Physics Conference Series 2018; 1049: 012009.

2. Lemma Y, Rantatalo M, Lundberg J. Top-of-rail friction measurements of the Swedish iron ire line. Proceedings of the $3^{\text {rd }}$ International Workshop and Congress on E-Maintenance, At Luleå, Sweden 2014.

3. Lewis R, Olofsson U. Wheel-rail interface handbook. Chapter 20. Maintenance of the wheel-rail interface. Woodhead Publishing in Mechanical Engineering 2009.

4. Zhu Y. Adhesion in the wheel-rail contact. Doctoral Thesis; Department of Machine Design. Royal Institute of Technology, Stockholm 2013.

5. Harmon M, Lewis R. Review of top of rail friction modifier tribology. Tribology: Materials, Surfaces and Interfaces 2016; 10 (3): 150-162.

6. Lewis S, Lewis R, Olofsson U, Eadie DT, Cotter J, Lu X. Effect of humidity, temperature and railhead contamination on the performance of friction modifiers: Pin-on-disk study. Proceedings of the Institution of Mechanical Engineers, Part F: Journal of Rail and Rapid Transit 2013;227: 115-127.

7. Faccoli M, Petrogalli C, Ghidini A. A Pin-on-disc study on the wear behaviour of two high-performance railway wheel steels. Tribology Letters 2017; 65: 152. 
8. Hayashi O, Nomura T, Nagase K. Influence of atmospheric conditions upon adhesion between rails and running wheels. Trans. Jap. Soc. Mech. Engrs, Part C 1997.

9. Olofsson U, Sundvall K. Influence of leaf, humidity and applied lubrication on friction in the wheel-rail contact: Pin-on-disc experiments. Proceedings of the Institution of Mechanical Engineers, Part F: Journal of Rail and Rapid Transit 2004; 218: $235-242$.

10. Ishida M, Aoki F, Sone Y, Ban T, Shirouzu K. Rail corrugations caused by low coefficient of friction in a submarine railway tunnel. Proceedings of the World Tribology Congress III, Washington, D.C. 2005: 931-932.

11. White BT, Lewis R, Olofsson U, Lyu Y. The contribution of iron oxides to the wetrail phenomenon. Proceedings of the Third International Conference on Railway Technology: Research, Development and Maintenance 2016; 110: 1-18.

12. Lee Y, Lee YC, Kim T, Choi JS, Park D. Sources and characteristics of particulate matter in subway tunnels in Seoul, Korea. Int. J. Environ. Res. Public Health 2018; 15: 2534 .

13. Querol X, Moreno T, Karanasiou A, Reche C, Alastuey A, Viana M. Variability of levels and composition of PM10 and PM2.5 in the Barcelona metro system. Atmos. Chem. Phys. 2012; 12: 5055-5076.

14. Zhu Y, Olofsson U, Chen H. Friction between wheel and rail: a pin-on-disc study of environmental conditions and iron oxides. Tribology Letters 2013; 52: 327-339.

15. Suzumura J, Yasutomo S, Ishizaki A, Yamashita D, Nakajima Y, Ishida M. In situ X-ray analytical study on the alteration process of iron oxide layers at the railhead surface while under railway traffic. Wear 2011; 271: 47-53.

16. Lyu Y, Zhu Y, Olofsson U. Wear between wheel and rail: a pin-on-disc study of environmental conditions and iron oxides. Wear 2015; 328-329: 277-285. 
17. Panda B, Balasubramaniam R, Vajpei AC, Srikanth S, Bhattachary A. Characterization of rust on microalloyed steel rail exposed to coastal location in India. Engineering, Science and Technology 2009; 44: 275-279.

18. Panda B, Balasubramaniam R, Moon A.. Materials Science and Technology 2009; 25: $1375-1382$.

19. Viesca JL, González-Cachón S, García A, González R, Battez AH. Tribological behaviour of microalloyed and conventional $\mathrm{C}-\mathrm{Mn}$ rail steels in a pure sliding condition. Proceedings of the Institution of Mechanical Engineers, Part F: Journal of Rail and Rapid Transit 2018; 232(9): 2201-2214.

20. Windart MB, Sudin KF. Influence of applied load on wear characterizations of rail material. J Appl Sci 2011; 11: 1636-1641.

21. Bronson-Lowe D, Bronson-Low CR. Making use of frequency tables and distributions. Winter. Prevention strategist 2016; 9(12): 32-37.

22. Blau PJ. Friction Science and Technology. CRC Press Taylor \& Francis Group 2009. 